\title{
The WI+RE Way: a manifesto and a process for learner-led design
}

Taylor Harper

Nisha Mody

Kian Ravaei

Renee Romero

Doug Worsham

UCLA

\begin{abstract}
WI+RE (Writing Instruction + Research Education) is a learner-led team of undergraduate and graduate student employees at UCLA Library who apply values-driven design principles and grassroots instructional media production techniques to foster breakthroughs in research, reading, and writing for their fellow learners. The WI+RE Way (UCLA Library WI+RE, 2019c) is a collaboratively authored manifesto for learner-led design co-authored by WI+RE's learner-designers in collaboration with library staff.
\end{abstract}

Keywords: values-driven design, learner-led design, design thinking, instructional design, interactive tutorials, critical pedagogy, student-centered pedagogy

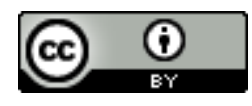

This is an Open Access article distributed under the terms of the Creative Commons Attribution 4.0 International License (http://creativecommons.org/licenses/by/4.0), which permits unrestricted use, distribution, and reproduction in any medium, provided the original work is properly cited. 


\section{Introduction}

In early 2015, UCLA Library was looking for a way to sustain a successful pilot project focused on creating learner-centered information literacy tutorials. The pilot project was led by a recently graduated female transfer student of color, who brought a passion for fostering academic success for students from diverse backgrounds. The project lead worked independently and then with small diverse teams of students to create a series of YouTube videos that received excellent feedback from instructors and students. This early feedback indicated that the videos were both pedagogically effective and personally relatable. Library staff and our campus partners were motivated to find a way to continue and expand on the work.

A group of cross-campus collaborators that included staff and faculty from the Library, the Undergraduate Research Centers, Writing Programs, and the Center for Digital Humanities came together to envision and create WI+RE (Writing Instruction + Research Education), a learner-led design team of undergraduate and graduate student employees, hosted by the Library. In the Fall of 2016, the first cohort of WI+RE learner-designers were hired, and began a collaborative training process that included foundational pedagogy, design principles, and grassroots media production.

Since 2016, WI+RE's process and approach have been developed and refined by three cohorts of learner-designers. To date, WI+RE's learner-designers have created a growing collection of open access instructional materials, including 7 online workshops, 20 tutorials, 9 handouts, and 1 interactive library exhibit. Instructional videos created during the pilot project (see Figure 1), and the subsequently developed workshops and tutorials, have been incorporated into multiple high enrollment classes across several campus disciplines. WI+RE's work has also been featured as a PRIMO (Peer-Reviewed Instructional Materials Online) Site of the Month (Ravaei, Marcyk, \& Worsham, 2019), and recognized in 
2018 with an "ARLie" for "Best Reflection of Diversity" at the ARL Film Festival (Association of Research Libraries, 2018). The success of these instructional materials is largely due to WI+RE's approach to learner-led design, which integrates values and pedagogy into each stage of the design process. This integrated approach developed over time, and has been influenced and improved by each of WI+RE's learner-designers. Similarly, the WI+RE Way manifesto did not exist when the team was initially formed.

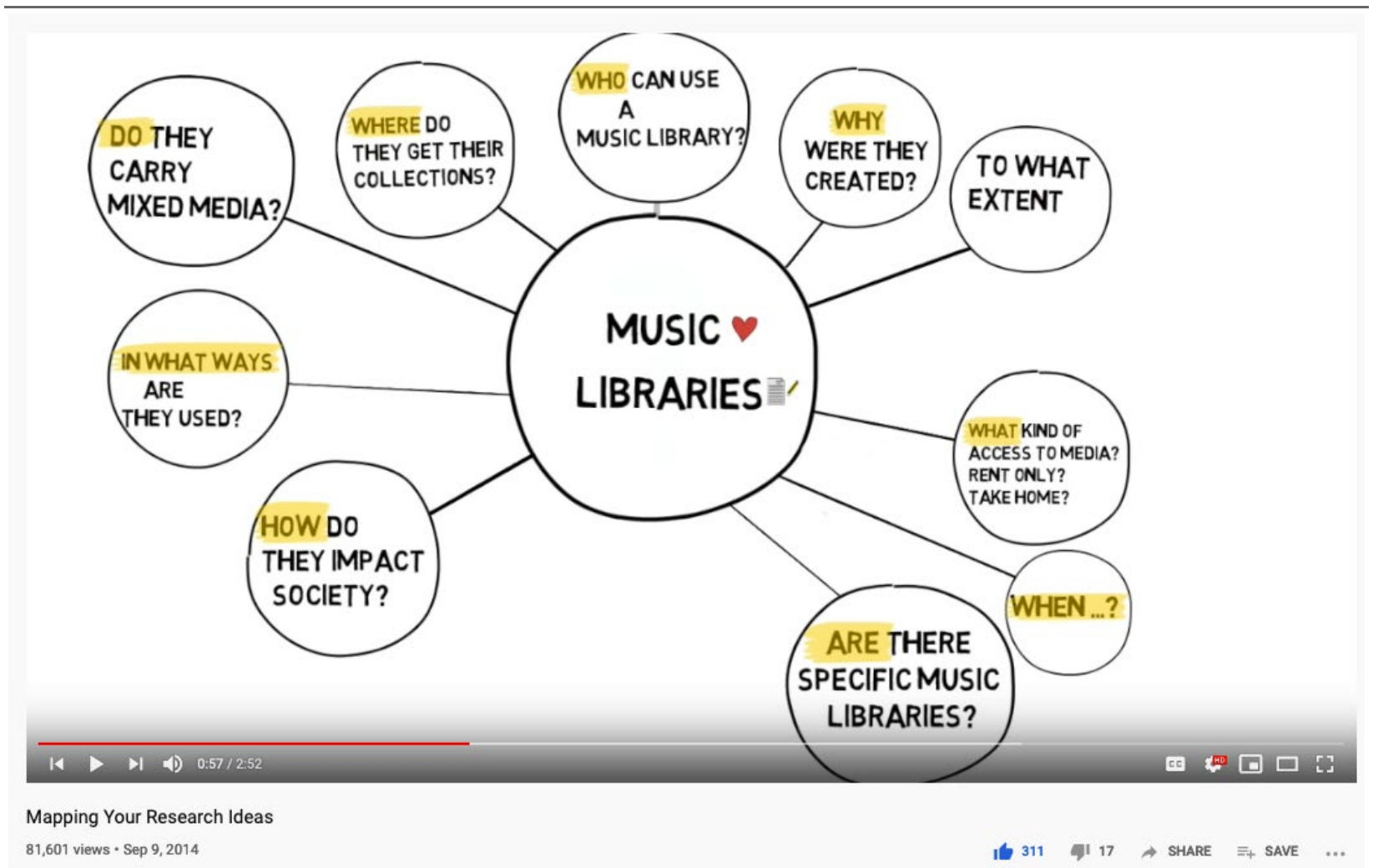

Figure 1: Mapping Your Research Ideas (Romero \& Worsham, 2014) was created as a part of the pilot project that led to the creation of WI+RE. To date it has been incorporated into course materials at several universities, and viewed over 81,000 times on YouTube.

Rather, our manifesto was created during a time of intentional reflection, in which the WI+RE team realized how frequently our most important challenges and questions were, at their core, valuesdriven. Through reflective inquiry on our work, the WI+RE team articulated the following questions 
about design, process, and pedagogy which later formed the basis for the WI+RE Way (Pierre, Harper, Meyer, Ravaei, \& Worsham, 2020):

- How do we create instructional materials that represent and celebrate the diversity of our campus and our communities?

- How do we work with divergent feedback collected through user-testing? How do we give empathetic and effective feedback to each other? How do we ensure that our work benefits from multiple perspectives?

- How do we create accessible learning experiences and more varied, inclusive pathways for learning? How do we prioritize universal design and accessibility throughout the design process?

As we reflected on these challenges and questions, we saw that we already had a set of shared values but had not yet written them down. We realized that by articulating and sharing our values, we could better advocate for the centrality of inclusive, transformative, and learner-centered pedagogy in libraries and higher education. At the same time, we could affirm and share aspects of our creative process that resist perfectionism, encourage DIY experimentation, and expand agency for learners as designers and creators of instructional materials. After co-creating an initial draft of the WI+RE Way, we made it a centerpiece of our training and design process, incorporating opportunities for the team to critique and revise it as our challenges and ways of working evolve.

The WI+RE Way manifesto is grounded in our belief that library work, teaching, and learning all involve design (Bowler et al., 2011), and that library workers, teachers, and learners can partner together to co-design instructional materials and learning experiences. Currently in its second major iteration, WI+RE's manifesto is both an ongoing work in progress and an essential part of our design process. 


\section{The WI+RE Way: Process, Pedagogy, and Values in Practice}

WI+RE's manifesto begins by affirming that our shared values guide our learning and design process. This reflects one of the key ideas that inspired the manifesto: that values, design, and pedagogy, while often thought of as distinct, are in fact interwoven. Each shared value in the WI+RE Way has been informed by pedagogical principles that often directly influence the design, process, or products of the WI+RE team. In the following paragraphs, we present each of the shared values statements that appear in the WI+RE Way, followed by discussion and examples of how the WI+RE team applies these values in practice.

\section{Foster memorable, meaningful, and transformative learning through learner-led design.}

We believe learning is most compelling when learners are leaders, designers, and cocreators of their learning experiences.

The pedagogical ideas at the heart of WI+RE's manifesto, "memorable, meaningful, and transformative learning," stem directly from WI+RE's grounding in active learning, constructivism, and critical pedagogy. These three pedagogical frameworks form the core of WI+RE's training program for new learner-designers and are integrated throughout our design process. This first statement in the manifesto also affirms the value of learner-led design and the importance of reframing learners as leaders and co-creators of their learning experiences. Here we owe homage to bell hooks (2010), whose critical reframing of the roles of learners and teachers is an inspiration for the WI+RE Way: "When everyone in the classroom, teachers and students, recognizes that they are responsible for creating a learning community together, learning is at its most meaningful and useful." 


\section{Values in practice}

WI+RE's integrated approach to values-driven design and pedagogy is most evident in Foundations in Learner-Centered Design (Worsham \& Roux, 2019), the open online mini-course that launches the training process for new learner-designers (Figure 2). As a team-based learning experience, the "Foundations" mini-course guides learners through a series of reflections on and conversations about their own learning experiences, and introduces key ideas in teaching and learning: active learning, constructivism, critical pedagogy, and universal design. From there, new learnerdesigners start using WI+RE's design process and tools for media production and web publishing (Worsham, 2019b), and simultaneously reflect on the roles of pedagogy and design values in each stage of the process. For WI+RE students, the mini-course culminates with the creation of a short, animated

\section{直国 Critical Pedagogy: Quotes for Reflection \& Discussion}

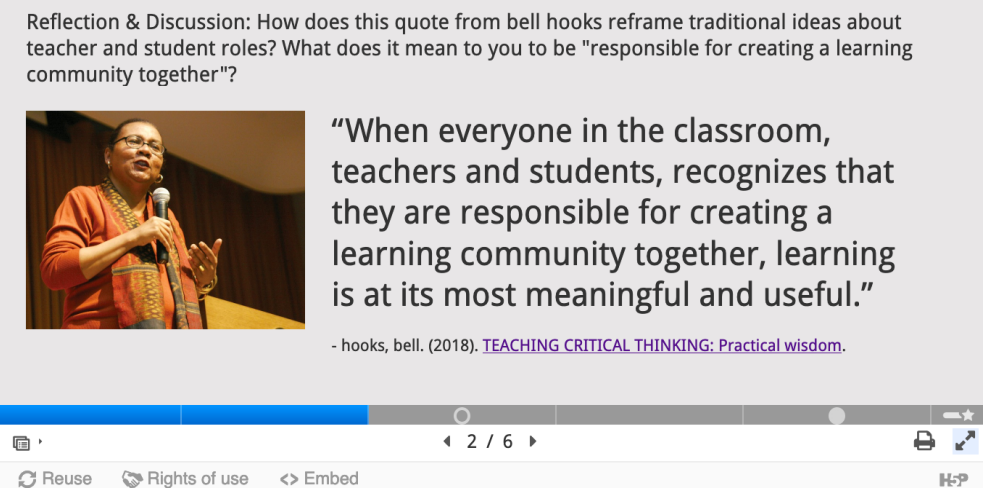

Figure 2: Foundations in Learner-Centered Design is the open online mini-course at the core of WI+RE's training program for learner-designers. It introduces constructivism, critical pedagogy, and universal design.

learning narrative video, illustrating a personally memorable, meaningful, or transformative learning experience (UCLA Library WI+RE, 2019b). 


\section{Build imperfect solutions quickly and on purpose.}

Rapidly creating publishable prototypes is more useful (and more fun) than striving for perfection.

Next, WI+RE's manifesto moves directly to one of our central design values: anti-perfectionism. Making imperfection intentional has been crucial for fostering creativity and confidence within our learner-designers. In recognizing that the instructional materials we create are unlikely to be perfect for all learners, we open ourselves up to the possibility that our work may be useful and helpful for some or many, and that over time, we can learn from feedback and improve.

We also introduce here the notion of a "publishable prototype." For WI+RE, this means that rather than aiming to "finish" our projects, we instead develop a series of gradually improving prototypes that are critiqued and evaluated by our community of library staff and campus partners, including UCLA's Center for Digital Humanities, our two Undergraduate Research Centers, Writing Programs, and the Writing Center. The collaborative pairing of our learner-designers with library and campus partner experts leads to significant revision and improvement throughout the prototyping process (Lee, Romero, \& Worsham, 2016). When WI+RE's learner-designers, library staff, and our campus partners agree we have reached a "publishable prototype," we publish it, and begin the process of course integration and further gathering of feedback. After publication, we continue to collect feedback and revise our work because we know there is no "finished" project: learners are constantly developing and changing, and we believe our materials should, as well. 
A visit to WI+RE's workspace offers a good opportunity to see WI+RE's anti-perfectionism and prototyping process in practice. We set up a project board for each of our active projects, and our learner-designers share the artifacts of their design process (e.g., Empathy Maps, Learning Journeys, and paper prototypes) with each other (Figure 3). In our projects, we encourage divergent thinking and experimentation, with the goal of nurturing multiple possible approaches. Early paper prototypes are further developed and then shared with our community partners online via email, feedback forms, and at face-to-face "design jam" sessions, where project progress, emerging questions, and constructive

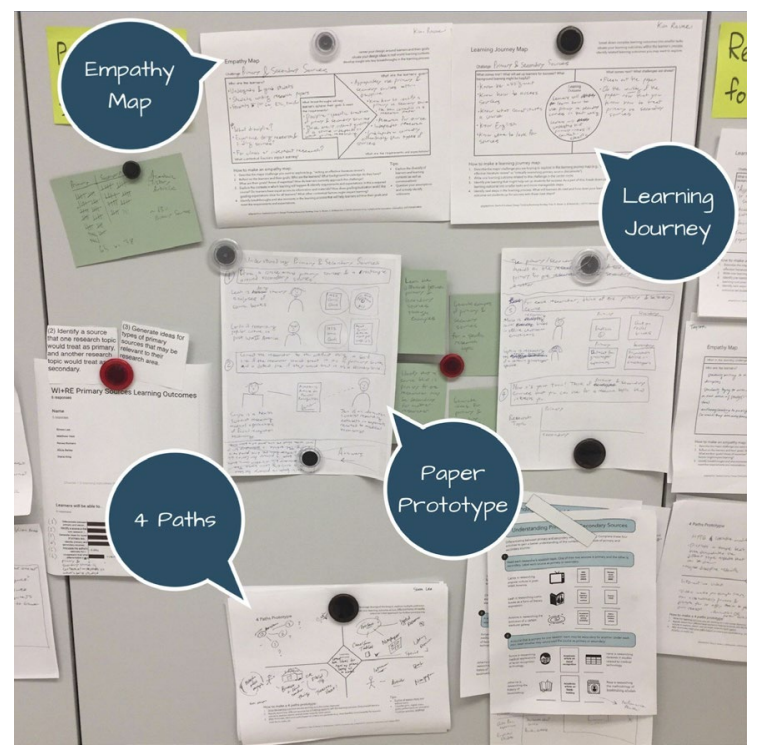

Figure 3: The project board for "Wheel of Sources" in the WI+RE workspace. Project boards allow WI+RE's learnerdesigners to collaborate on each stage of the design process, from empathy mapping to prototyping.

comments are shared between collaborators. The team of learner-designers gathers and discusses the feedback, and then works to converge around more specific approaches in subsequent rounds of prototyping. We resist the expectation that our work be "perfect" at any stage of the process, instead aiming to improve our work and build upon feedback. 


\section{Be quick and practical.}

Everyone's got stuff to do, so let's get right to it.

As a learner-led initiative, WI+RE has always been focused on authentic learner experiences, challenges, and breakthroughs. As our learner-designers reflect on and discuss their learning experiences, a persistent insight about our campus learning communities comes to the fore again and again: our learners have a lot going on. Their academic work is happening in the context of very active lives, which include employment, service, families, clubs, social groups, and hopefully some time to relax and reflect. As such, it has been important for WI+RE to emphasize in our design process that we want to produce instructional materials that don't plod along or get in people's way. Instead, we strive to be upbeat and helpful, reminding ourselves that learners are looking to us not for entertainment, but for practical approaches to overcoming important challenges.

WI+RE's focus on quick and practical learning can be seen by browsing our Research Tutorials Playlist on YouTube (Figure 4, UCLA Library WI+RE, 2019a). Thematically, this playlist covers several of the most common challenges identified by our learner-designers and community partners, from time management and articulating a research question, to finding research opportunities on campus and learning more about other undergraduate students who have completed research projects. Averaging less than three minutes per video, WI+RE's YouTube playlist aims to provide students with quick access to practical, learner-centered tips and strategies for addressing common research and writing challenges. 

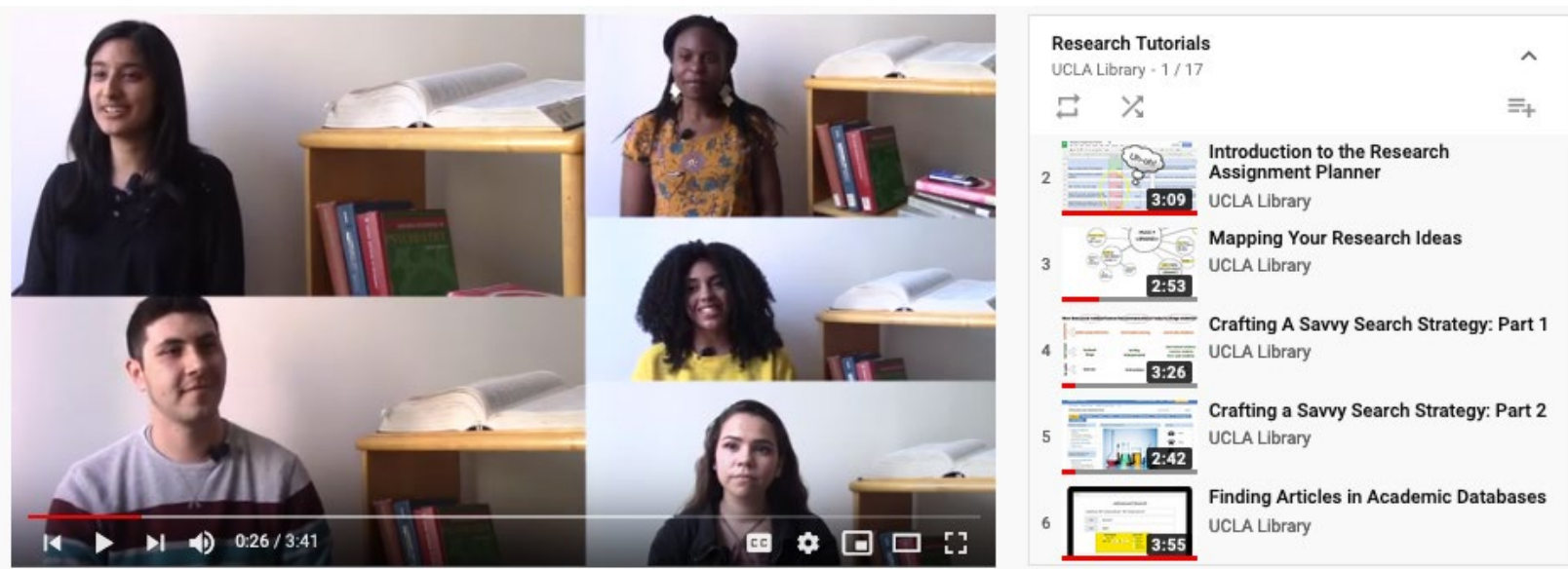

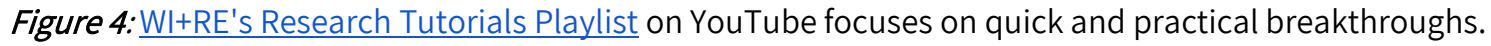

\section{Reveal hidden challenges and expedite breakthroughs.}

Sometimes the syllabus doesn't say it all. We try to make hidden challenges easier to see by breaking down the research and writing process into manageable tasks.

Is it possible to be both "quick and practical" and "transformative"? WI+RE has tried to address this challenge by focusing our work on hidden challenges that may not be covered in the syllabus or made readily apparent for all learners in a class. Our learner-designers frequently reflect on and discuss the ways that the most important challenges and breakthroughs leading to student success are often not taught directly, or even indirectly, in their courses. Self-identifying as a researcher, applying the expected social conventions when emailing a faculty member, and successfully collaborating with a research mentor are all hidden challenges that, though not commonly addressed in classroom instruction, could be among the most important and transformative for learners and researchers. Each of these breakthroughs may also be a key to opening up further and more transformative learning down the line. For WI+RE, breaking down complex processes and decoding higher education is an 
essential part of fostering inclusive excellence. In uncovering hidden aspects of the curriculum, WI+RE strives to identify and foster breakthroughs in learning, and create learning experiences that are "quick and practical" as well as "transformative."

One of WI+RE's most popular resources, Quick Tips for Contacting Instructors Over Email (Figure 5, Roux, Ravaei, \& Harper, 2019), has received extensive attention on social media from both students and instructors. For this project, the WI+RE team decided to create a simple PDF guide, rather than a video, to make it easier for students to reference while crafting an

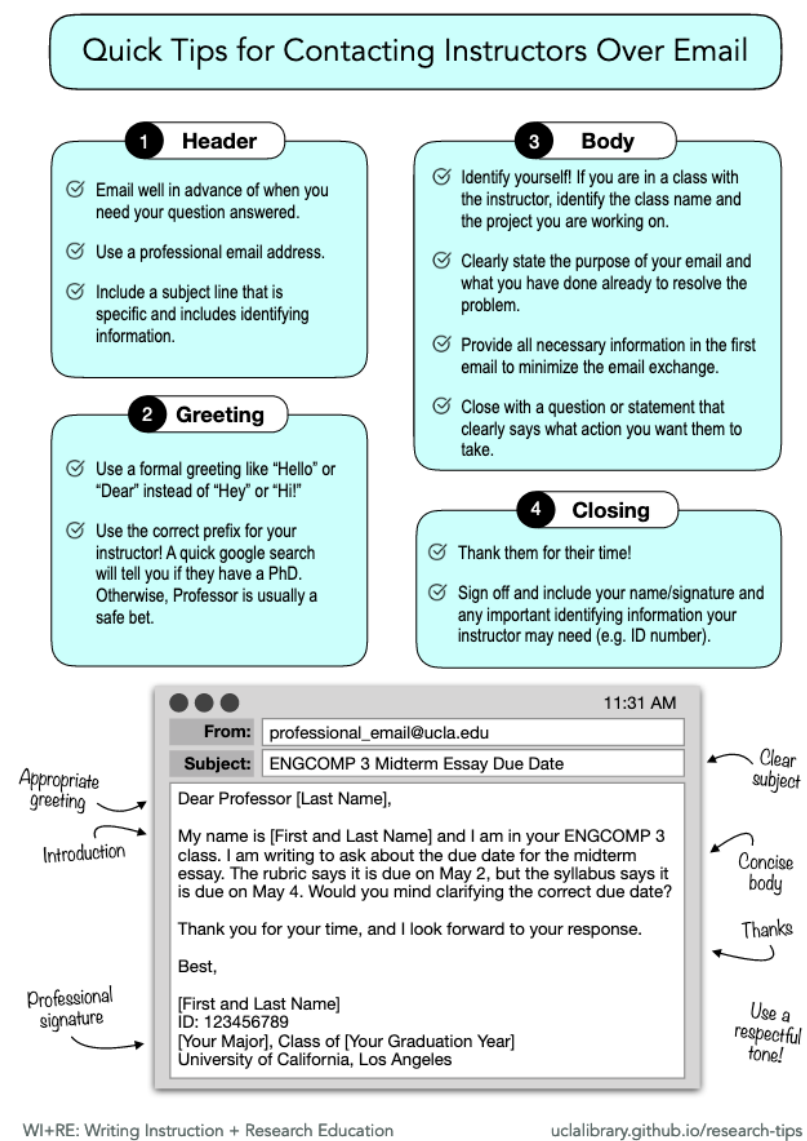

Figure 5: Quick Tips for Contacting Instructors Over Email is a practical resource on a topic not usually covered in a course syllabus

email message. The popularity of this guide reflects the importance of revealing and addressing hidden challenges and breakthroughs in higher education, as well as the need for simple and practical guides 
on topics not covered in a typical syllabus. For more examples of other WI+RE modules that directly address hidden challenges, see our "Reading Strategies" playlist (UCLA Library WI+RE, 2018a) and the "Entering Research" Workshop series (Ravaei, Yan, Burns, \& Lin, 2019), which includes modules on communication skills and practices essential for success with undergraduate research projects.

\section{Experiment with what we have on hand.}

We explore \& implement DIY approaches to learning design and media making. We tinker, try new things, and explore. We use tools and try out processes we have never used before, and frequently make it up as we go.

\section{Pursue universal design at every stage of the process.}

Accessibility and usability are not checkboxes at the end of a project, but areas of continual importance that can always be improved.

\section{Design multiple pathways for learning.}

Learning happens in many formats, from videos and animations to printable handouts and interactive exhibits. When we create something that seems to be helpful in one format, we try to adapt it to work in another.

Experimentation and evolution have been more important for WI+RE than establishing a consistent "brand" for our work. The WI+RE team is constantly changing and evolving as learnerdesigners move on to new positions and graduate from the university. This means that new ideas and perspectives continually inform our work. At the same time, the tools and technologies for designing interactive learning experiences evolve as well. Rather than working with a fixed toolset, WI+RE aims for a design process that "provides ample creative freedom within well-designed pathways" (Worsham, 2019a). The team constantly expands their technical skills, experimenting with unfamiliar media and 
using an ever-growing set of design software. We have a built-in expectation that every project will involve figuring it out as we go, and that we will always learn something new when designing and creating together. That is not to say that our process is haphazard or chaotic. While we do take a DIY approach, every project also benefits from a set of processes that help ensure our values inform our work. These are the "well-designed pathways" that take the form of multiple community reviews of prototypes and a team-wide dedication to promoting equity and inclusivity.

WI+RE's design approach and values are also fundamentally focused on universal design, accessibility, and usability. This focus on the importance of accessible learning materials for diverse learners and approaches to learning begins in our training program and is incorporated throughout our design process, from the initial empathy mapping stage and our prototyping and community review process, to multiple checks along the way to make sure our videos are captioned, our images have alt-text, our interactive slideshows are keyboard navigable, and all of our work is updated based on new approaches to providing accessible pathways to learning for all.

In our design process, we often reflect on how delivering learning outcomes and activities in multiple formats recognizes that learning happens in a variety of contexts and that diverse learners have diverse learning needs. In addition to providing both interactive media and text/PDF based approaches to the same learning outcomes, WI+RE has sought to deliver learning in a variety of modalities. By providing materials in our campus course management system, through our open website, on YouTube, and in physical library spaces, we're trying to meet learners where they are. And, in offering both short tutorials covering 1-2 learning outcomes, and "workshop-sized" interactive modules addressing four or more learning outcomes, we are trying to provide a variety of teaching and learning options for both instructors and students. 
WI+RE's interactive poster series and accompanying social media campaign (Figure 6, Pierre \&

Ravaei, 2019) is an example of experimentation across multiple modes of engagement to provide multiple pathways for diverse learners. This six-week poster series featured a new question each week focusing on a different aspect of the research process, ranging from "What are your favorite strategies for choosing a research topic?" to "What are your favorite strategies for writing a reference list or works cited page?" Students at four different library locations placed stickers on a poster to indicate their favorite answers to the question or annotated the poster with a provided pen to add their own answers and ideas. Students could further interact with the poster by flipping open some of the provided answers to discover a link to a relevant library service, tutorial, or resource. Each week ended with the publication of a summary video, sharing the most popular answers and linking directly to helpful

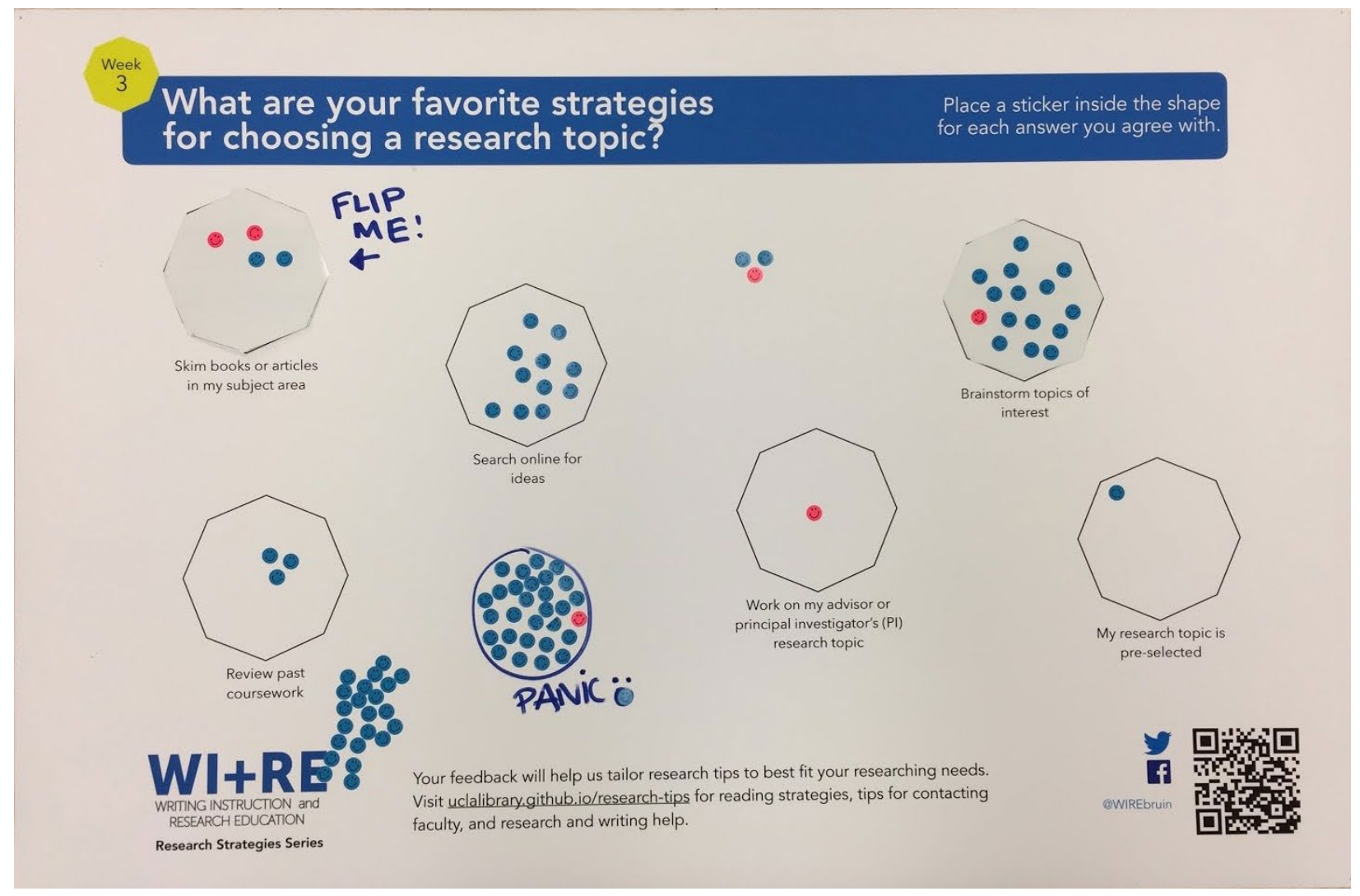

Figure 6:WI+RE's interactive poster series experimented with engaging students in conversation about the research and writing process in both physical spaces and online. 
resources (UCLA Library WI+RE, 2018b). In total, the interactive posters in library spaces gathered 859 responses from students, including 72 "write-in" responses in which students annotated the poster with their own ideas. This project is a good example of WI+RE's learner-designers experimenting with new approaches and providing both online and in-person pathways for engaging in dialogue with learners and researchers.

Wheel of Sources (Figure 7, Ravaei \& Pierre, 2018), an interactive tutorial focused on helping students differentiate primary and secondary sources, was another project that presented design questions and challenges for the WI+RE team. Early on, it became clear that clarifying the varying disciplinary definitions of "primary" and "secondary" was essential for this project. WI+RE's learner-designers and community partners also wanted the tutorial to be an interactive game in which players analyzed the concepts of "primary" and "secondary" from the perspectives of multiple

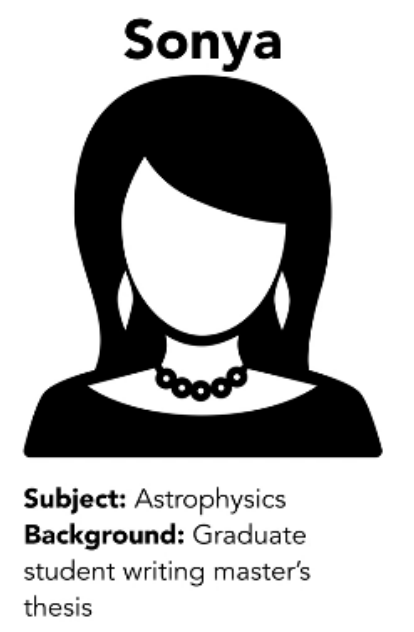

\section{Research Topic: Evolution of starburst galaxies}

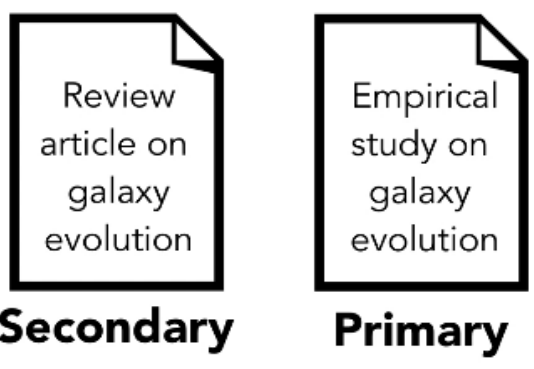

summarizes and reinterprets information found in empirical studies.

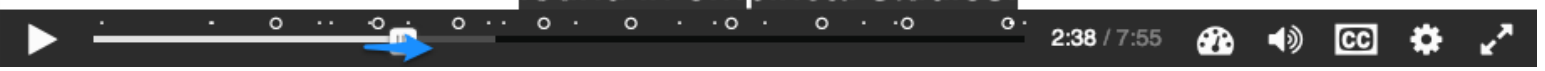

Figure 7: Wheel of Sources challenges students to differentiate primary and secondary sources from the perspectives of researchers across a variety of disciplines. 
researchers. The learner-designers for the project created several prototypes, from $3 \times 5$ cards to small computer programs. After extensive testing, prototyping, and community review, the team decided to leverage H5P, an open source software toolkit, because it offered the desired game-like interactivity and was also compatible with course management software on campus. That said, as we reviewed our H5P prototypes, we were initially not sure that they were accessible. The H5P prototypes relied on a "drag-and-drop" dynamic that, if not implemented with accessibility guidelines in place, can be challenging or even impossible for learners that do not use a mouse to navigate their computers. The WI+RE team got in touch with the H5P developers to determine that the drag and drop component in the H5P toolkit was indeed keyboard navigable, and met accessibility standards for the web. At the same time, WI+RE developed an accessible PDF version of the activity, providing learners and teachers with another option to pursue the same learning outcomes. The behind-the-scenes work on this project demonstrates WI+RE's approach to experimentation with new modes of engagement and creating multiple accessible learning pathways for different learners and learning contexts.

\section{Speak with our own voices.}

We're learners, not voice actors. We avoid "tutorial voice" and instead share our work in our own varied voices.

\section{Celebrate our diverse communities.}

We celebrate the diversity of our communities through positive, inclusive, and relevant pedagogy. 
WI $+R E$ is comprised of a diverse team of learners who create for diverse communities. We realize that when we embrace our identity as a team of learners with multiple perspectives and identities rather than trying to force ourselves to fit a mold, we create tutorials that are more authentic, relevant, and representative of both our team and the community. Thus, we strive to subvert the paradigm of a teacher or authoritative figure feeding knowledge to a student, and instead frame tutorials as a learner sharing helpful tips with another learner. This communication style is reflected both in the conversational way we speak in our videos and the way we style our writing, using easily comprehensible language even if at times it means sounding non-academic.

The diversity of perspectives on the WI+RE team also fosters diversity of representation in our learning modules. Our shared value to intentionally celebrate our diverse campus communities is grounded in ongoing efforts to consciously center the narratives of a variety of students from underrepresented groups, including first-generation students and minority populations on campus (Romero, Worsham, \& Pho, 2019). Implicit biases often reflect systemic biases, thus positive representation of women and other minority communities on university campuses can help address structural inequality (Vuletich \& Payne, 2019) and disrupt white heteronormative narratives, which is important to help students from marginalized backgrounds feel represented and successful within and beyond their campus communities (Dasgupta \& Asgari, 2004; Madva, 2020). In our work, we recognize that the who, how, and why of representation deeply matters, and directly impacts the relatability, relevance, and reach of WI+RE's work specifically, as well as of library services in general (Bonnet \& McAlexander, 2012).

One of our early video tutorials, Saving Newspaper Articles to Zotero (Meyer \& Harper, 2016), was instrumental in the development of WI+RE's shared-values to "speak with our own 
voices" and "celebrate our diverse communities." This video (Figure 8), like most of our media tutorials, features two student narrators, reinforcing that the information is being shared from and informed by multiple people and perspectives. The voiceover style is energetic and enthusiastic, but still natural and sincere. Rather than switching into a "tutorial" or "presentation" voice, we strive to speak in our own voices and from our own perspectives and identities as learners. This two-speaker approach underscores "speaking with our own voices"

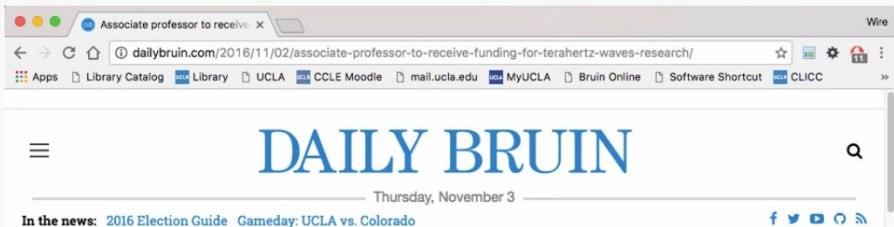

Associate professor to receive funding for terahertz waves research
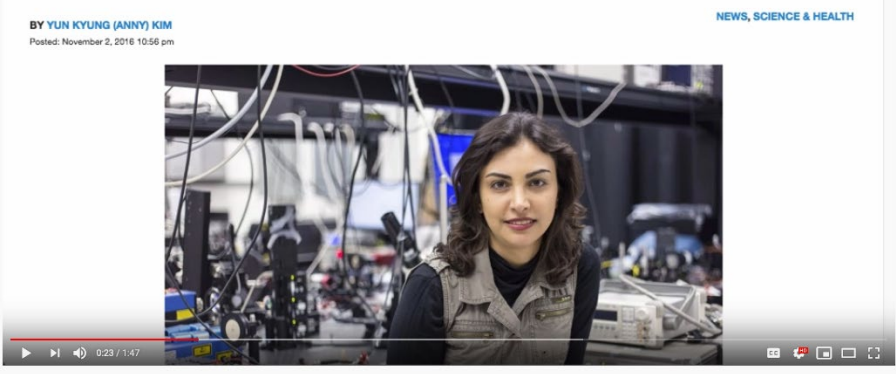

Saving Newspaper Articles and Blog Posts to your Zotero Collection

Saving Newspaper Articles and Blog Posts to your Zotero Collection
220 viens - Nov 15,2015

Figure 8: While creating the tutorial Saving Newspaper Articles and Blog Posts to your Zotero Collection the WI+RE team focused on representing and celebrating diverse campus communities.

and is a part of our efforts to represent and celebrate the multiplicity of voices in our campus communities.

Furthermore, we intentionally chose examples and visual elements for the video that celebrate the diverse communities on our campus, while also being inclusive and relevant. Our early prototypes featured national news coverage of a presidential election campaign. While these examples were timely in some respects, as we critiqued our prototypes, we realized that featuring our campus community was much more important and relatable than referencing 
the already amplified discourse of political news coverage. In addition, we realized we could use our platform to support inclusivity and representation on campus by featuring underrepresented voices, communities, and perspectives in our tutorials. In order to better represent and celebrate our diverse campus communities, we changed our examples in this tutorial to feature a student-authored post on a campus departmental blog and a news story from our student-run campus newspaper featuring an underrepresented faculty researcher in STEM. As such, representation in this video works on multiple levels: we hear the student voices of the narrators and creators of the tutorial itself, we see student-authored content presented during the tutorial, and one of the examples features the award-winning work of UCLA electrical engineering professor Mona Jarrahi and her work on terahertz waves. How we addressed the design challenge of choosing relevant and relatable content in this video tutorial became a model for future projects, and significantly informed the articulation of our shared values in the WI+RE Way.

\section{Collaborate creatively.}

We use a rich and growing toolkit of design tools to collaborate and partner with learners, researchers, librarians, and teachers throughout the creative process.

\section{Share our work and engage with the world}

Our work is open source and can be shared, re-used, and re-mixed. In each of our projects we seek to make a difference for learners, researchers, and writers.

A creative and evolving approach to collaboration has been an important part of WI+RE'S success. Our team of learner-designers have variable schedules, and each project involves extensive 
communication with people and communities across campus. We strive to follow a thoughtful design process for each project, and to create, share, and discuss our extensive notes and documentation as we work. We also strive to openly share both the outcomes of our work, and the process that leads to their creation.

Each of WI+RE's projects begins with a collaborative exploration of the learner experience, progressing from empathizing with learners, narrowing and specifying learning outcomes, brainstorming multiple learning pathways, creating initial prototypes, and gathering and analyzing feedback. The "Build Something Toolkit" (Brecher Cook \& Worsham, 2018), as featured on WI+RE's "Design Tools" page (Figure 9), provides extensive documentation of this process, including worksheets, directions, and examples for each step. For a narrative example of this design toolkit in use, see the short video, The Making of Wheel of Sources (Ravaei, 2019). This quick video provides visual examples of the prototyping and community review process, showing how the project developed over time, and sharing perspectives on the process from the creator's point of view. WI+RE seeks to foster conversations about the potential for learner-centered and learner-led design by openly publishing our instructional materials, toolkits, and narratives about our creative process. Opening up our work and our process also provides opportunities for WI+RE to further emphasize the learnerin learner-led design, and to advocate for others to center learners and learning in their educational work. Thus far, over 26,000 people from 162 different countries have visited the WI+RE website, and WI+RE's instructional modules have been used and adapted by library and university staff from several countries. In creating "embeddable" versions of our instructional modules and licensing our materials through Creative Commons, WI+RE encourages others to use and customize our work. WI+RE hopes that through sharing our tools, process, stories, and instructional 
materials, we will empower others to launch their own learner-centered and learner-led design teams and projects.

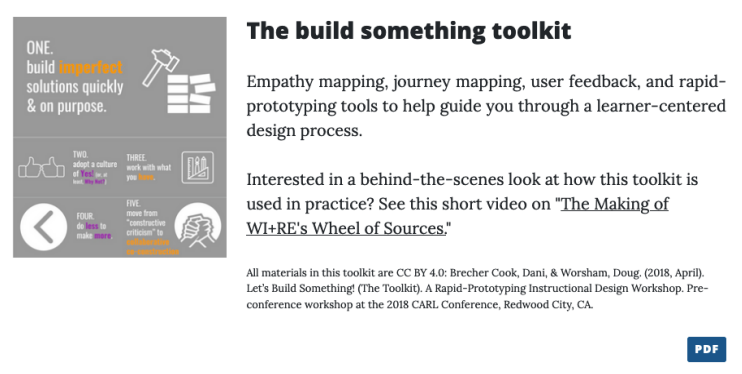

Figure 9:WI+RE's design tools, training materials, and manifesto are all publicly available on our site.

\section{From the WI+RE Way to YourWay}

We believe every team hoping to do creative work benefits from making a manifesto, as there is no neutrality in design. Values are always in play, whether intentionally or unintentionally, when creators work together (Flanagan, Howe, \& Nissenbaum, 2005; Flanagan \& Nissenbaum, 2014; Gray \& Boling, 2016). We have found that intentionally co-authoring a manifesto of shared values has helped our team create with more thought and purpose, and we believe it has also led to more compelling, more ethical, and ultimately more useful designs.

This is not to say that making a manifesto makes design work easy-creative and collaborative projects are teeming with challenges. Creating a manifesto does, however, provide a framework that helps creators ask and answer difficult questions, work through challenges, and resolve conflicts. It can also help you and your team articulate the integrated relationships between pedagogy, process, and values in your work (Friedman, Kahn, \& Borning, 2002; Knobel \& Bowker, 2011).

We share our manifesto not with the hope that you will adopt it, but rather that you will adapt it, or even better, set it aside and create your own. We believe that when shared values guide the design process, designers discover unconventional pathways, generate more relevant ideas, and 
produce compelling and transformative results. If you are creating with others and forothers, you are working with values. Everyone benefits when those values are made visible and are a living part of the creative process. So please, get together with your team, talk about whyand howyou work together, and write out a first draft of your shared values.

\section{References}

Association of Research Libraries. (2018, April 24). ARL Film Festival 2018-The "Arlies." Retrieved November 18, 2019, from Association of Research Libraries website: https://www.arl.org/arlfilm-festival-2018/

Bowler, L., Koshman, S., Oh, J. S., He, D., Callery, B. G., Bowker, G., \& Cox, R. J. (2011). Issues in usercentered design in LIS. Library Trends, 59(4), 721-752. https://doi.org/10.1353/lib.2011.0013 Brecher Cook, D., \& Worsham, D. (2018, April). Let's Build Something (The Toolkit). Retrieved from https://ucla.app.box.com/v/build-something-toolkit

Flanagan, M., Howe, D., \& Nissenbaum, H. (2005). Values in design: Theory and practice. Retrieved from http://citeseerx.ist.psu.edu/viewdoc/download;jsessionid=68B7C88F3848D8EA3D18A47606BC

\section{C392?doi=10.1.1.89.6460\&rep=rep1\&type=pdf}

Flanagan, M., \& Nissenbaum, H. F. (2014). Values at play in digital games.

Friedman, B., Kahn, P. H., \& Borning, A. (2002). Value sensitive design: Theory and methods. UW CSE Technical Report, 8.

Gray, C. M., \& Boling, E. (2016). Inscribing ethics and values in designs for learning: A problematic. Educational Technology Research and Development, 64(5), 969-1001. https://doi.org/10.1007/s11423-016-9478-x

hooks, bell. (2010). Teaching critical thinking: Practical wisdom. New York: Routledge. 
Knobel, C., \& Bowker, G. C. (2011). Values in design. Communications of the ACM, 54(7), 26. https://doi.org/10.1145/1965724.1965735

Lee, S., Romero, R., \& Worsham, D. (2016, August). Engaging campus partners to Ddevelop a hybrid toolkit for student success. Poster presented at the National Diversity in Libraries Conference, Los Angeles, CA. Retrieved from http://ndlc.info/program/Thursday Posters/Engaging-

\section{Campus-Partners-to-Develop-a-Hybrid-Toolkit-for-Student-Success}

Meyer, C., \& Harper, T. (2016). Saving newspaper articles and blog posts to your zotero collection. Retrieved from https://www.youtube.com/watch?v=bAHeMkNNKsQ

Pierre, J., \& Ravaei, K. (2019). Intersecting surveys and fun: Reducing library anxiety in a library poster survey series. Presented at the SCIL Works 2019, California State University, Dominguez Hills. Retrieved from https://uclalibrary.github.io/research-tips/sandbox/research-process-posterseries/

Ravaei, K. (2019). The making of WI+RE's “Wheel of Sources. "Retrieved from https://www.youtube.com/watch?v=hfkG4bWjRml\&feature=youtu.be

Ravaei, K., Marcyk, E., \& Worsham, D. (2019, March 1). Wheel of sources-March 2019 site of the month interview. Retrieved April 1, 2019, from ACRL's Instruction Section Website website: https://acrl.ala.org/IS/instruction-tools-resources-2/pedagogy/primo-peer-reviewedinstruction-materials-online/primo-site-of-the-month/march-2019-site-of-the-month/

Ravaei, K., \& Pierre, J. (2018). Wheel of sources. Retrieved from https://uclalibrary.github.io/researchtips/primary-secondary/

Ravaei, K., Yan, X., Burns, G., \& Lin, R. (2019, November). Entering research workshop series. Retrieved November 13, 2019, from https://ccle.ucla.edu/course/view/wire?section=3 
Romero, R., \& Worsham, D. (2014). Mapping your research ideas. Retrieved from https://www.youtube.com/watch?v=jjF6YVtsxl\&list=PLV8eqWoGXke5D5bmwscUhow1RJKWZmMRZ\&index=4\&t=49s

Romero, R., Worsham, D., \& Pho, A. (2019, May 11). Better together: Student-led collaborative media creation [Presentation]. LOEX 2019, Minneapolis, MN. https://dmcwo.github.io/dmcwo/presentations/better-together-student-led-media

Roux, S., Ravaei, K., \& Harper, T. (2019, February 25). Contacting instructors-WI+RE. Retrieved November 13, 2019, from https://uclalibrary.github.io/research-tips/handouts/ContactingInstructors/

UCLA Library WI+RE. (2018a). Reading strategies with WI+RE[YouTube video]. Retrieved from https://www.youtube.com/channel/UCRPedAkolOOC6z-iP2S-clQ

UCLA Library WI+RE. (2018b, October 30). Week 1 poster series tweet. Retrieved November 13, 2019, from Twitter website: https://twitter.com/wirebruin/status/1057364574695878656?ref_url=https\%3a\%2f\%2fuclalibr ary.github.io $\% 2$ fresearch-tips $\% 2$ fsandbox $\% 2$ fresearch-process-poster-series $\% 2 f$

UCLA Library WI+RE. (2019a). Research tutorials playlist. Retrieved from https://www.youtube.com/playlist?list=PLV8eqWoGXke5D5bmwscUhow1RJKWZmMRZ

UCLA Library WI+RE. (2019b). WI+RE learning narratives playlist. Retrieved from https://www.youtube.com/playlist?list=PLV8eqWoGXke7bbWJPk3LBlvTmQuuWqt3J

UCLA Library WI+RE. (2019c). WI+RE's manifesto-WI+RE. Retrieved May 13, 2019, from https://uclalibrary.github.io/research-tips/wire-way/ 
Worsham, D. (2019a, June 24). WI+RE: Creating a learner-led instructional design team in your library. Presented at the American Library Association Annual Conference, Washington, D.C. Retrieved from https://eventscribe.com/2019/ALAAnnual/fsPopup.asp?Mode=PresInfo\&PresentationID=496362

Worsham, D. (2019b, June 23). WI+RE's tech toolbox (a snapshot). Retrieved June 23, 2019, from WI+RE Sandbox website: https://uclalibrary.github.io/research-tips/sandbox/wire-tech-toolbox/

Worsham, D., \& Roux, S. (2019). Foundations in learner-centered design. Retrieved April 22, 2019, from https://uclalibrary.github.io/foundations 